\title{
An Exploratory Examination of Student to Professor Disclosures of Crime Victimization
}

\author{
Tara N. Richards', Kathryn A. Branch'2, \\ and Rebecca M. Hayes ${ }^{3}$
}

\begin{abstract}
Prior qualitative research has demonstrated that female college students may utilize their professors as support providers when they experience sexual assault and intimate partner violence victimization. To further explore this phenomenon, the present study used a random sampling design on two college campuses to examine the following questions: (a) Are student disclosures of crime victimization a common occurrence for college professors? (b) What is the nature of college professors' most recent disclosure of crime victimization? and (c) Do professor characteristics predict receiving a student disclosure of victimization? Implications of these findings as well as directions for future research will be discussed.
\end{abstract}

\section{Keywords}

college students, help-seeking, sexual assault

Research focusing on college campus crime has concluded that overall college and university crime rates are significantly lower than those of the surrounding communities (Bromley, 1995; Hart, 2007; Volkwein, Szelest, \& Lizotte, 1995). When college students do experience crime victimization, it is most often a nonviolent crime, such as property crimes (e.g., theft of personal belongings; Bromley, 1995). One critical exception to these findings pertains to forms of gendered violence (also referred to as

\footnotetext{
'Appalachian State University, Boone, NC, USA

2University of Tampa, FL, USA

${ }^{3}$ Central Michigan University, Mount Pleasant, USA

Corresponding Author:

Tara N. Richards, School of Criminal Justice, University of Baltimore, I 420 N. Charles Street, LAP 507,

Baltimore, MD 2I20I, USA.

Email:TrichalI@gmail.com
} 
gender-specific violence or gender-based victimization) such as stalking, domestic violence, and sexual assault (Hart, 2007). These forms of violence are considered to be gendered violence as they are typically male-on-female violence and are, at least in part, a product of our society's patriarchal structure (Morash, 2006). Thus, female college students may experience a more acute risk for gender-based victimization in their otherwise "safe" college community (Armstrong, Hamilton, \& Sweeney, 2006; Fisher, Cullen, \& Turner, 2000, 2002; Humphrey \& White, 2000).

Extant research suggests that the majority of survivors of rape and sexual assault disclose their victimization to informal support providers including family, friends, and significant others, rather than formal agencies such as law enforcement and victim advocates (Campbell, Wasco, Ahrens, Sefl, \& Barnes, 2001; Fisher, Daigle, Cullen, \& Turner, 2003; Starzynski, Ullman, Filipas, \& Townsend, 2005). However, many female college students are removed from their network of loved ones and, as a result, may reach out to their college professors for support post-victimization. Recent qualitative research examined student disclosures to female faculty in the social sciences and revealed that some students are going to their professors for support post-sexual assault or-domestic violence victimization (Hayes-Smith, Richards, \& Branch, 2010). Findings further indicate that some faculty members routinely receive student disclosures of gendered crime victimization. However, questions still exist as to the occurrence of this phenomenon among male faculty and faculty from other academic disciplines. Using a sample of male and female professors from a range of academic specialties, the present study investigates the occurrence of student disclosures of crime victimization to college professors, the nature of their most recent disclosure, and what, if any, professor characteristics predict receiving a student disclosure.

\section{Prevalence of Gendered Violence on College Campuses}

Research suggests that between $20 \%$ and $25 \%$ of college women are raped during their academic career (Fisher et al., 2000; Humphrey \& White, 2000; Krebs, Lindquist, Warner, Fisher, \& Martin, 2009). As many as 9 in 10 college women who are sexually assaulted know the attacker (Fisher et al., 2000) with self-report studies indicating that male acquaintances, friends, and boyfriends pose the most salient risk to female students (Gross, Winslett, Roberts, \& Gohm, 2006; Ward, Chapman, Cohn, White, \& Williams, 1991). The presence of the attacker in a survivor's circle of friends/acquaintances may further complicate her post-assault response and recovery.

In addition to the increased rate of sexual assault in college populations, literature on domestic violence in college communities demonstrates that one in five students has personally experienced domestic violence (Bogal-Allbritten \& Allbritten, 1985; Cate, Henton, Koval, Christopher, \& Lloyd, 1982; Stets \& Pirog-Good, 1987). Moreover, a recent study by Amar and Gennaro (2005) found that almost half of the female students at two U.S. universities reported experiencing violence from an intimate partner.

Research has also suggested that stalking is often associated with sexual assault, domestic violence, and femicide (Fisher et al., 2002). The existing literature 
demonstrates that young women are the primary victims of stalking and that most victims know their stalker (Coleman, 1997; Fisher et al., 2002; Mustaine \& Tewksbury, 1999; Tjaden \& Thoennes, 1998). For example, Mustaine and Tewksbury (1999) reported that $10.5 \%$ of their sample of 861 female college students indicated experiencing behavior that they self-defined as "stalking," while Fisher et al. (2002) reported that $13.1 \%$ of 4,446 female college students sampled reported being stalked in a single academic year.

Although recent efforts have been made to uncover the amount of gendered violence experienced by college women, existing statistics are likely gross underestimates of the "true" number of victimizations involving college students. There is consensus among most experts that official reports of sexual assault (including police and Uniform Crime Report [UCR] records) underestimate the amount of gendered violence experienced by women (Fisher et al., 2002; Krebs et al., 2009). This suggests that the overwhelming majority of sexual assault and domestic violence victims are not reporting their victimization to official support providers such as campus security or law enforcement. This finding is consistent with recent research by Hart (2007), demonstrating that college students rarely report violent victimization to law enforcement.

\section{College Student Disclosure of Victimization}

Post-victimization, college students may not know where to turn for help. Existing research suggests that post-assault, the majority of survivors of rape and sexual assault turn to informal support providers like family and friends (Ahrens, 2006; Ahrens, Campbell, Ternier-Thames, Wasco, \& Sefl, 2007; Golding, Siegel, Sorenson, Burnam, \& Stein, 1989). However, college is a place where students are often separated from their informal support systems. For example, research on young adults' transition from high school to college has uncovered a phenomenon coined "friendsickness" such that college students experience distress and anxiety when they move away from their established group of friends and attempt to create a new circle of close friends (Paul \& Brier, 2001).

In addition, college students may not want to tell their parents about victimization experiences. College students may feel like they can take care of themselves, or at least feel like they should show their parents they can. Experiencing victimization may make college students feel like they failed to live up to the expectation of self-sufficiency and they may be ashamed to reach out to their parents for assistance. To illustrate, results from the National College Women Sexual Victimization Study indicated that $44 \%$ of female students did not report a completed rape to police or the school because they did not want their family to know (Fisher et al., 2000; Fisher et al., 2003). Lacking an inherent support system post-victimization, college students may reach out to someone with whom they have established rapport. For many college students, this may be a professor.

A recent qualitative study found that female professors/instructors were receiving disclosures from students regarding sexual assault or domestic violence experiences, 
and more than half of those disclosing appeared to be in crisis (Hayes-Smith et al., 2010). The present research provides the first opportunity to uncover whether studentto-professor disclosure is a faculty-wide/campus-wide phenomenon or is concentrated among female faculty from specific disciplines. This information could be instrumental in gaining the support of administration regarding training/programming for professors on student victimization and disclosure.

\section{Student Choices for Disclosures: Does Professor Gender Matter?}

An impetus for student disclosure to a specific professor may be the professor's gender. Specifically, a student may approach a female professor because of traditional gender role expectations that prescribe that women should be relationship oriented, compassionate, and responsible for providing emotional support (Bem, 1983; Hoffman, 1997). In addition, gender role obligations may translate into female faculty, making a concerted effort to create and establish a relationship with students, extend an open door policy to students, and listen when students come to them with personal problems or concerns. A national survey of college teachers indicates that almost half $(46 \%)$ of the female faculty members, compared with $33 \%$ of male faculty members, report striving to aid in the emotional development of their students (Lindholm, Szelenyi, Hurtado, \& Korn, 2005). Female professors, compared with male faculty members, report spending more hours focused on their students, preparing for and teaching classes, and advising their students (Lindholm et al., 2005).

Research demonstrates that there are gender differences in teaching styles for male and female faculty. A hallmark of such differences is female faculty's desire to cooperate, bond, and connect with students (Bress, 2000). Bress (2000) asserts that "women feel more comfortable sharing their expertise with others rather than rivaling others with it" (p. 27). Furthermore, research by Berry (1989) indicates that female faculty members may "generate more classroom discussion, more interaction, and more give and take" than male faculty members (as quoted by Goodwin \& Stevens, 1993, p. 169). As such, college classrooms led by female faculty may have a greater sense of community to disclose personal information such as crime victimization. Conversely, male professors assume a lecturing role that minimizes student opportunity for such disclosure (Fox, 1990).

The effect of prescribed gender roles may not only impact a faculty member's teaching style, but may also influence the classes taught. According to the 2005 Higher Education Research Institute National Norms for College Faculty Survey, female professors were more likely to teach classes in the social sciences, education, and liberal arts, classes that may focus on sensitive topics, compared with classes in business, mathematics, and the sciences. Thus, the combination of female faculty members' increased likelihood of emphasizing cooperative learning and openly discussing sensitive subject matter such as sexual assault or family violence may create an especially attractive space for students to disclose crime victimization. 


\section{The Present Study}

The present research builds on previous qualitative findings that have documented that some students are approaching their female faculty in the social sciences with disclosures of sexual assault and domestic violence victimization (Hayes-Smith et al., 2010). Our goal is to add to the empirical literature on student-to-professor disclosure by investigating student-to-professor disclosures of crime victimization in a sample of male and female faculty that teach in a variety of disciplines. Specifically, the present study examines the following research questions:

Research Question 1: Are student disclosures of crime victimization a common occurrence for college professors?

Hypothesis 1: Student disclosure of crime victimization to their college professors is a frequent occurrence, and a portion of professors will receive multiple disclosures.

Research Question 2: What is the nature of college professors' most recent disclosure of crime victimization?

Hypothesis 2: The majority of student disclosures will take place in a professor's office and will be provoked by a specific incident in class. A minority of students will ask for leniency as a result of the disclosure.

Research Question 3: Do professor characteristics predict receiving a student disclosure of victimization?

Hypothesis 3: Female professors and professors who teach sensitive topics will receive significantly more student disclosures of crime victimization compared with male professors and professors who do not teach sensitive topics.

\section{Method}

\section{Procedure}

Professors from two U.S. universities were contacted via an email solicitation inquiring whether they had ever received a student disclosure of crime victimization. At University 1, two waves of data collection took place due to the sizable number of faculty on staff. The first wave included an initial email to a random sample of 300 professors and two follow-up emails asking for participation. This elicited a sample of 126 participants ( $42 \%$ response rate). To increase the sample size, another random sample of 200 professors was sent an initial solicitation email and two follow-up emails. This elicited a final sample size of 180 participants, for an overall response rate of approximately $36 \%$ for University $1 .{ }^{1}$ At University 2, an initial email and two follow-up emails asking for participation were sent to all 260 full-time faculty members. This elicited a sample of 81 participants for a response rate of $31 \%$ at University 2 .

In the call for participants, professors were asked to respond to the survey whether they had ever received a disclosure or not. The survey was posted on a widely used website, surveymonkey.com. After signing in, participants were asked to read the 
informed consent. Participants indicated consent by clicking on the "agree" button to start the survey. Participants then filled out the questionnaire with the ability to skip any questions they did not wish to answer. On the final screen, participants were thanked for their participation.

\section{Measures}

Student disclosures. Participants were initially asked, "Have you ever had a student disclose to you that he or she has been the victim of a crime?" Next, participants were specifically asked, "Have you ever had a student disclose any type of sexual violence or domestic violence?" Both these questions were dummy coded with $0=$ no and $1=$ yes. Participants were then asked whether they had received more than one disclosure and prompted to indicate the number of disclosures they had received. In addition, participants were asked an open-ended question concerning the types of crime disclo-sures they received; participants could list as many crime types as necessary.

The nature of student disclosure. To capture more detailed information regarding student disclosure, we asked numerous questions concerning the participant's most recent disclosure. We asked the following questions: where the disclosure took place (in your office, via email, in an assignment, on a discussion board, in class, or other), whether the participant believed a specific topic or incident provoked the student to disclose, whether the student asked for leniency, whether or not the university had the resources to respond to student disclosures of victimization, and whether the participant knew their University's policy on rape and sexual assault.

Teaches sensitive topic. Participants were asked a yes or no question regarding whether they "teach courses on crime, victims, assault, gender, and/or sexuality."

Political affiliation. Political affiliation was captured using a self-reported threeitem measure (liberal $=1$, moderate $=2$, conservative $=3$ ).

Age. Age was self-reported by participants in years.

\section{Sample}

The overall sample $(N=261)$ was comprised of 116 females $(49 \%)$ and 118 males (51\%) (see Table 1). In comparison, institutional statistics for the two universities demonstrate that they employ $44 \%$ female and $56 \%$ male faculty, and $43 \%$ female and 57\% male faculty, respectively. An additional 27 professors declined to report their gender. The overwhelming majority of the sample identified their race/ethnicity as "White/Non-Hispanic" $(n=215,82 \%)$, while 5 (2\%) identified as "Asian," $3(1 \%)$ as "Black/Non-Hispanic," and $3(1 \%)$ as Hispanic. The overall racial make-up of the universities' faculties indicates that professors are $87 \%$ and $80 \%$ White, respectively. Participants ranged in age from 22 to 89 years old with a mean age of 45 years old. In 
Table I. Demographics.

\begin{tabular}{lcc}
\hline Variable & Total sample $(N=26 \mathrm{I}), N(\%)$ & Disclosure sample $(N=1$ I 0$), N(\%)$ \\
\hline Gender & & $5 I(46 \%)$ \\
Female & $116(44 \%)$ & $46(42 \%)$ \\
Male & $118(45 \%)$ & \\
Race & & $91(98 \%)$ \\
White & $215(94 \%)$ & $1(1 \%)$ \\
Black & $3(1 \%)$ & $1(1 \%)$ \\
Asian & $5(2 \%)$ & - \\
Hispanic & $3(1 \%)$ & - \\
Other & $2(1 \%)$ & $24-87,48$ \\
Age & $22-89,45$ & $8(7 \%)$ \\
Range, $M$ & $22(8 \%)$ & $18(16 \%)$ \\
Teaching area & $42(16 \%)$ & - \\
Business/law & $9(3 \%)$ & $6(5 \%)$ \\
Math/sciences & $21(8 \%)$ & $19(17 \%)$ \\
Sports/recreation & $49(19 \%)$ & $2(2 \%)$ \\
Education & $4(1.5 \%)$ & $20(18 \%)$ \\
Liberal arts & $44(17 \%)$ & $28(29 \%)$ \\
Health/nutrition & $47(20 \%)$ & $70(71 \%)$ \\
Social sciences & $191(80 \%)$ & \\
Teaches sensitive topics & & \\
Yes & & \\
No & &
\end{tabular}

addition, $47(18 \%)$ professors reported teaching classes on sensitive topics such as crime, victims, and/or gender/sexuality. Almost equal numbers of male and female faculty indicated teaching sensitive topics: $23(10 \%)$ and $24(10 \%)$, respectively.

\section{Results}

We first examined how many participants had ever received a student disclosure of any type of crime. Findings indicated that 110 participants (42\%) reported receiving a student disclosure of crime victimization, 148 (57\%) participants had not, and $3(1 \%)$ could not remember. Among participants who had received a student disclosure, 30 (27\%) participants reported receiving multiple disclosures. An almost equal number of male $46(42 \%)$ and female $51(46 \%)$ participants reported receiving a student disclosure of crime victimization. Only 28 (29\%) participants who had received a student disclosure taught courses on topics such as crime, victims, and/or gender/sexuality. A range of different types of crimes were disclosed to participants. The top five most frequently disclosed crimes included rape and sexual assault (42\%), assault (18\%), theft (15\%), domestic violence (6\%), and sexual harassment and stalking (both $3 \%$, respectively). 
Table 2. Participant's Most Recent Student Disclosure.

\begin{tabular}{lc}
\hline Variable & $N(\%)$ \\
\hline Mechanism for disclosure & $40(73 \%)$ \\
Participant's office & $4(7 \%)$ \\
Email & $4(7 \%)$ \\
Assignment & - \\
Discussion board & $3(6 \%)$ \\
In class & $4(7 \%)$ \\
Other & \\
Belief that disclosure was provoked & $34(55 \%)$ \\
Yes & $28(45 \%)$ \\
No & \\
Asked for leniency & $13(32 \%)$ \\
Yes & $28(68 \%)$ \\
No & \\
Adequate university resources & $24(36 \%)$ \\
Yes & $16(24 \%)$ \\
No & $26(39 \%)$ \\
"I don't know" & \\
Yes & $48(89 \%)$ \\
No & $6(11 \%)$ \\
\hline
\end{tabular}

The nature of participants' most recent disclosure is presented in Table 2. Participants had received their most recent student disclosure in multiple ways: $73 \%$ of students had come to a participant's office, $7 \%$ of students disclosed crime victimization via email or in an assignment, $6 \%$ disclosed during class, and 7\% disclosed in "other" ways. Approximately $55 \%$ of participants believed that their most recent student disclosure had been provoked by a specific topic or incident that occurred in class. In addition, $68 \%$ of participants responded that the student who disclosed did not ask for any form of leniency on assignments. When asked whether their university had sufficient resources to assist students, only $36 \%$ of participants reported that they believed their university had these resources. In addition, of participants who had received a disclosure, the majority (89\%) reported knowing their university's policy on sexual assault.

To determine whether professor characteristics, including teaching sensitive topics and/or professors' gender, significantly predicted student disclosures of crime victimization, both bivariate and multivariate statistical techniques were utilized. First, means tests were conducted to determine if there was a bivariate relationship between receiving a student disclosure and gender and/or teaching sensitive topics, as well as several control variables including age in years, race, teaching area, and the political identification measure. Results are reported in Table 3. Analyses indicated that there was a significant bivariate relationship between receiving a student disclosure of crime 
Table 3. Bivariate Results for Student Disclosure.

\begin{tabular}{lcc}
\hline Variable & Pearson $\chi^{2}$ & $p$ value \\
\hline Age & 52.656 & .372 \\
Gender & 0.895 & .639 \\
Political identification & 0.493 & .781 \\
Sensitive topics & 7.719 & .005 \\
\hline
\end{tabular}

Table 4. Logistic Regression Results for Student Disclosure.

\begin{tabular}{lcccccc}
\hline & & & & & \multicolumn{2}{c}{$95 \% \mathrm{Cl}$} \\
\cline { 6 - 7 } Variable & $B$ & SE & Wald & Odds Ratio & Lower limit & Upper limit \\
\hline Age & -.035 & .013 & 7.658 & $0.965^{* *}$ & 0.941 & 0.990 \\
Gender & .218 & .308 & 0.499 & NA & 0.679 & 2.276 \\
Political identification & .030 & .216 & 0.019 & NA & 0.675 & 1.571 \\
Sensitive topics & .965 & .382 & 6.375 & $2.625^{*}$ & 1.241 & 5.552 \\
$\chi^{2}$ & $15.184^{* *}$ & & & & & \\
-2 Log likelihood & 243.456 & & & & & \\
\hline
\end{tabular}

Note. $73 \%$ of cases $(N=190)$ were correctly predicted by the model. $*_{p}<.05 . * * p<.01$.

victimization and both teaching sensitive topics $\left(\chi^{2}=7.719, p=.005\right)$ and age $(t=$ $3.10, p=.002)$. Teaching sports and recreation was significantly related to never receiving a student disclosure $\left(\chi^{2}=6.931, p=.008\right)$.

Next, a logistic regression analysis was estimated to investigate the relationship between receiving a student disclosure and variable of interest (gender and teaching sensitive topics) net of the other variables. Professors' self-reported age in years and political identification were included in the model as control variables. Table 4 presents the findings. Results indicate that teaching sensitive topics and age were significant predictors of professors receiving a student disclosure of crime victimization. First, professors who taught sensitive topics were 2.63 times more likely to receive a student disclosure than professors who did not teach sensitive topics. Second, as professors' age increased, the odds of receiving a student disclosure of crime victimization was reduced by 0.97 . Professors' gender and political affiliation were not significantly related to receiving a student disclosure of crime victimization.

\section{Discussion}

There were several findings that emerged from our data. First, as predicted, the current data suggest that student disclosures are a common occurrence, at least for these two particular institutions. Forty-two percent of the overall sample reported that they had received a student disclosure of crime victimization. In addition, almost one in three 
participants who had received a student disclosure reported receiving multiple student disclosures. Moreover, approximately two thirds of the participants who reported receiving a student disclosure of crime victimization indicated that their most recent student disclosure was of gendered violence (e.g., sexual assault or domestic violence). The data also suggest that student disclosures are a campus-wide phenomenon. Participants from a range of academic disciplines reported receiving student disclosures of crime victimization. This finding is consistent with the current literature indicating that (a) sexual assault and domestic violence is an important problem in college communities (Fisher et al., 2000; Humphrey \& White, 2000; Krebs et al., 2009) and (b) victims of gendered crime are likely to seek assistance from informal support providers (Campbell et al., 2001), including their professors (Branch, Hayes-Smith, \& Richards, 2011; Hayes-Smith et al., 2010).

Second, as predicted, the majority of student disclosures occurred in a professor's office, were believed to have been provoked by a specific topic or incident in class, and the majority of students did not ask for leniency when they disclosed. The finding that the majority of students did not ask for leniency when they disclosed victimization to their professors may help dispel the myth that students "create" personal problems with the hopes of gaining leniency from their professors. It is also important to note that $14 \%$ of students disclosed crime victimization via email or in an assignment. Professors may find it particularly difficult to respond appropriately to a student disclosure of crime victimization when it is embedded in a student's assignment. Previous research has noted that professors struggle with grading an assignment that contains a disclosure because they want to remain an objective grader but, at the same time, they do not want to further traumatize the student-survivor (Branch et al., 2011). Finally, many participants who had received a student disclosure indicated that they were not confident in the resources available at their university for crime victims. Taken together, these findings demonstrate the need to disseminate information to professors about both on- and off-campus resources for crime victimization, especially resources for sexual assault and intimate partner violence.

Third, there were no significant differences between male and female participants in terms of their likelihood to receive a student disclosure of any crime victimization. This finding is inconsistent with our predictions and with previous literature focused on differences in male and female teaching styles, and their impact on a student's comfort level with a professor (see, for example, Bress, 2000; Fox, 1990). This suggests that student disclosures are not just a "woman's issue" and that both male and female faculty from a variety of academic disciplines should be prepared to receive a disclosure of crime victimization from their students. As predicted, participants who reported teaching sensitive topics were more likely to receive a student disclosure compared to other participants who did not teach sensitive topics. This finding is consistent with prior research demonstrating that teaching sensitive topics may create a safe space for students to discuss personal information such as crime victimization (Durfee \& Rosenberg, 2009). Findings from the present study suggest that both male and female professors who teach classes that discuss sensitive topics must be prepared to receive student disclosures of crime victimization. 
Finally, the data indicate that younger participants reported experiencing disclosures at an increased rate compared with older participants. It is possible that younger faculty members are more likely to be new to campus and may lack familiarity with victim resources on campus and in the community. Younger faculty members may also be unsure about their department's position on the facilitation of students' "personal problems" and may be reluctant to help a student out of fear that it is outside the purview of their professional role.

\section{Future Research and Limitations}

Future research must examine why students are choosing professors as their source of support post-victimization and whether or not professors provide the support students are looking for. In addition, what are students' expectations of professors when they disclose crime victimization? Present findings indicate that the majority of students are not looking for leniency from their professors, but there has been no research to date focused on what students do need. Finally, given that younger faculty are more likely to receive student disclosures, future research should further investigate the role of a professor's age as a predictor of student disclosure. It may be that students are more likely to identify with younger faculty as both mentors and perhaps even friends.

Several limitations of the current research should be noted. First, the present study utilized the phrase "crime victimization"; however, some professors may not define what was disclosed to them as crime victimization, especially if the student does not define their experience as such. This is even more likely with regard to gendered crimes such as domestic violence or sexual assault that are rarely identified as crimes by the victims themselves (Fisher et al., 2003). Similar to research on the "dark figure of crime," future research on student-to-professor disclosure could use probing questions and more specific wording to help reveal the "true figure" of student disclosures. Likewise, the current survey asked whether participants had ever received a disclosure, meaning that the disclosure(s) could have occurred at any time during a participant's career. Thus, the significant impact of (younger) age could be even more pronounced if older faculty were describing a disclosure that occurred earlier in their careers. Future research could ask participants about their age at the time of each disclosure.

Some may question our use of an online survey versus a more traditional mail survey. This criticism is particularly pertinent with regard to the Dillman's method (1991) that promises an $80 \%$ response rate when using telephone and mail surveys. However, others have argued for the use of online surveys, as telephone surveys are becoming increasingly outdated due to the increase of cellular phone usage and the decrease in need for home telephones (Farrell \& Petersen, 2010).

A final limitation of the present research is the use of only two universities for data collection in this study. The sizable number of student disclosures could be due to characteristics of the two universities sampled; however, the institutions varied in terms of their size (small vs. mid-level), geography (south vs. midwest), and type (private vs. public). Although in-depth investigations of the universities' specific characteristics are beyond the scope of the current exploratory research, the current sample 
was representative of the overall universities' faculty populations with regard to race and gender distribution. Future research could examine the relationship between student-to-professor disclosures and institutional characteristics such as institutional programming and faculty-student ratios, as well as individual professorial characteristics such as favored teaching styles and methods or lecture versus discussion format. Universities with more racially/ethnically diverse faculties may also yield different findings. It would be helpful if questions regarding student-to-faculty disclosures were integrated into the national college student victimization survey, so that this phenomenon may be examined among university climates across the nation.

\section{Conclusion}

The present research suggests that student-to-professor disclosures may be a common occurrence on college campuses. Although the present findings indicate certain professor characteristics may be related to receiving a student disclosure, comprehensive predictors for this phenomenon have yet to be uncovered. It is our hope that the current exploratory study will open the dialogue regarding faculty experiences with student disclosures of crime victimization. We believe that our research points to the need for nationally representative research to fully explore this important phenomenon. Specifically, future studies must include student perspectives as to their needs when disclosing crime victimization to professors. Collectively, such findings could be instrumental in creating campus programming and training for faculty and administrators with regard to student-to-professor disclosure.

\section{Authors' Note}

Portions of this research were presented at the 2011 meeting of the Academy of Criminal Justice Sciences, Toronto, Canada.

\section{Acknowledgments}

The authors wish to thank the anonymous reviewers as well as Molly Dragiewicz and Walter DeKeseredy for their helpful input on this manuscript.

\section{Declaration of Conflicting Interests}

The author(s) declared no potential conflicts of interest with respect to the research, authorship, and/or publication of this article.

\section{Funding}

The author(s) received no financial support for the research, authorship, and/or publication of this article.

\section{Note}

1. It is difficult to calculate a separate response rate for the second round because we cannot know whether professors from the first round responded after the second round was contacted. 


\section{References}

Ahrens, C. (2006). Being silenced: The impact of negative social reactions on the disclosure of rape. American Journal of Community Psychology, 38, 263-274.

Ahrens, C., Campbell, R., Ternier-Thames, N., Wasco, S., \& Sefl, T. (2007). Deciding whom to tell: Expectations and outcomes of rape survivors' first disclosures. Psychology of Women Quarterly, 31, 38-49.

Amar, A. F., \& Gennaro, S. (2005). Dating violence in college women: Associated physical injury, healthcare usage, and mental health symptoms. Nursing Research, 54, 235-242.

Armstrong, E., Hamilton, L., \& Sweeney, B. (2006). Sexual assault on campus: A multilevel, integrative approach to party rape. Social Problems, 53, 483-499.

Bem, T. B. (1983). Androgyny and gender: Schema theory a conceptual an empirical integration. In T. B. Sonderegger \& A. Anastasi (Eds.), Psychology and gender (pp. 179-226). Lincoln: University of Nebraska Press.

Berry, E. (1989, April). Taking women professors seriously. Paper presented at the annual meeting of the American Association for Higher Education, San Francisco, CA.

Bogal-Allbritten, R. B., \& Allbritten, W. L. (1985). The hidden victims: Courtship violence among college students. Journal of College Student Personnel, 26, 201-204.

Branch, K. A., Hayes-Smith, R., \& Richards, T. N. (2011). Professors' experiences with student disclosures of sexual assault and domestic violence: How "helping" students can inform teaching practices. Feminist Criminology, 6, 54-75.

Bress, P. (2000). Gender differences in teaching styles. Forum, 38(4), 26-29.

Bromley, M. (1995). Comparing campus and city crime rates: A descriptive study. American Journal of Police, 14, 131-148.

Campbell, R., Wasco, S. M., Ahrens, C. E., Sefl, T., \& Barnes, H. E. (2001). Preventing the "second rape": Rape survivors' experiences with community service providers. Journal of Interpersonal Violence, 16, 1239-1259.

Cate, R. M., Henton, J. M., Koval, J., Christopher, F. S., \& Lloyd, S. (1982). Premarital abuse. Journal of Family Issues, 3, 79-90.

Coleman, F. L. (1997). Stalking behavior and the cycle of domestic violence. Journal of Interpersonal Violence, 3, 420-432.

Dillman, D. A. (1991). The design and administration of mail surveys. Annual Review of Sociology, 17, 225-249.

Durfee, A., \& Rosenberg, K. (2009). Teaching sensitive issues: Feminist pedagogy and practice of advocacy-based counseling. Feminist Teacher, 19, 103-120.

Farrell, D., \& Petersen, J. C. (2010). The growth of internet research methods and the reluctant sociologist. Sociological Inquiry, 80, 114-125.

Fisher, B., Cullen, F., \& Turner, M. (2000). The sexual victimization of college women (U.S. Department of Justice, Office of Programs, National Institute of Justice Research Report). Retrieved from http://ncjrs.gov/pdffiles1/nij/182369.pdf

Fisher, B., Cullen, F., \& Turner, M. (2002). Being pursued: Stalking victimization in a national study of college women. Criminology \& Public Policy, 1, 257-308.

Fisher, B., Daigle, L., Cullen, F., \& Turner, M. (2003). Reporting sexual victimization to the police and others: Results from a national-level study of college women. Criminal Justice and Behavior, 30, 6-38.

Fox, T. (1990). Gender interests in reading and writing. In T. Fox (Ed.), The social use of writing: Politics and pedagogy (pp. 51-70). Norwood, NJ: Ablex.

Golding, J., Siegel, J., Sorenson, S., Burnam, M., \& Stein, J. (1989). Social support sources following sexual assault. Journal of Community Psychology, 17, 92-107. 
Goodwin, L. D., \& Stevens, E. A. (1993). The influence of gender on university faculty members' perceptions of "good" teaching. Journal of Higher Education, 64, 166-185.

Gross, A., Winslett, A., Roberts, M., \& Gohm, C. (2006). An examination of sexual violence against college women. Violence Against Women, 12, 288-300.

Hart, T. C. (2007). Violent victimization of college students: Findings from the National Crime Victimization Survey. In J. Sloan \& B. Fisher (Eds.), Campus crime: Legal, social, and policy perspectives (2nd ed.) (pp.129-146). Springfield, IL: C.C. Thomas.

Hayes-Smith, B., Richards, T. N., \& Branch, K. (2010). But I am not a counselor: The nature of role strain experienced by female professors when a student discloses sexual assault and intimate partner violence. Enhancing Learning in the Social Sciences, 2(3): SSN: 1756$848 \mathrm{X}$

Hoffman, M. L. (1997). Sex differences in empathy and related behaviors. Psychological Bulletin, 84, 712-722.

Humphrey, J. A., \& White, J. W. (2000). Women's vulnerability to sexual assault from adolescence to young adulthood. Journal of Adolescent Health, 27, 419-424.

Krebs, C., Lindquist, C. H., Warner, T. D., Fisher, B., \& Martin, S. L. (2009). College women's experiences with sexual assault before and since entering college. Journal of American College Health, 57, 639-649.

Lindholm, J. A., Szelenyi, K., Hurtado, S., \& Korn, W. S. (2005). The American college teacher: National norms for the 2004-2005 HERI Faculty Survey. Los Angeles, CA: Higher Education Research Institute, UCLA.

Morash, M. (2006). Understanding gender, crime and justice. Thousand Oaks, CA: Sage.

Mustaine, E. E., \& Tewksbury, R. (1999). A routine activity theory of explanations for women's stalking victimizations. Violence Against Women, 5, 43-62.

Paul, E. L., \& Brier, S. (2001). Friendsickness in the transition to college: Precollege predictors and college adjustment correlates. Journal of Counseling \& Development, 79, 77-89.

Starzynski, L. L., Ullman, S. E., Filipas, H. H., \& Townsend, S. M. (2005). Correlates of women's sexual assault disclosure informal and formal support sources. Violence and Victims, 20, 417-432.

Stets, J. E., \& Pirog-Good, M. A. (1987). Violence in dating relationships. Social Psychology Quarterly, 50, 237-246.

Tjaden, P., \& Thoennes, N. (1998). Prevalence, incidence, and consequences of violence against women: Findings from the National Violence against Women Survey (Department of Justice, Office of Programs, National Institute of Justice Research Report). Retrieved from http://www.ncjrs.gov/pdffiles/172837.pdf

Volkwein, J., Szelest, B., \& Lizotte, A. (1995). The relationship of campus crime to campus and student characteristics. Research in Higher Education, 36, 647-670.

Ward, S. K., Chapman, K., Cohn, E., White, S., \& Williams, K. (1991). Acquaintance rape and the college social scene. Family Relations, 40, 65-71.

\section{Author Biographies}

Tara N. Richards is an assistant professor in the School of Criminal Justice at the University of Baltimore. Her major research interests include violence against women; mental health, substance abuse, and trauma/violence; and evaluation research. Some of her most recent published work appears in Crime \& Delinquency, Journal of Interpersonal Violence, and Women \& Criminal Justice. She is the recipient of the 2011 American Society of Criminology Division on Women and Crime's graduate scholar award. 
Kathryn A. Branch is an associate professor in the department of Criminology and Criminal Justice at the University of Tampa. Her research interests include the impact of sexual assault on secondary victims such as faculty and friends of survivors and the role of social support in women's use of aggression against an intimate partner. Her recent research is featured in Feminist Criminology, Journal of Interpersonal Violence, and ELiSS.

Rebecca M. Hayes is an associate professor in the department of Sociology, Anthropology, and Social Work at Central Michigan University. Her research interests include violence against women; race, gender, and class issues in the criminal justice system; and the media's influence on society. Her recent research is featured in Feminist Criminology, Critical Criminology, and Contemporary Justice Review. 